\title{
AVALIAÇÃO MULTIDISCIPLINAR E PROJETO PARTICIPATIVO: ESTUDO DE CASO DO INTERIOR HABITACIONAL DE UM APARTAMENTO
}

\author{
POLLESEL, Maria Cristina Torres (1); \\ FALCÃO, Christianne Soares (2) \\ (1) Universidade Católica de Pernambuco, Aluna da graduação em Arquitetura e Urbanismo \\ e-mail: cristinapollesel.ara@gmail.com \\ (2) Universidade Católica de Pernambuco, Doutora em Design UFPE \\ e-mail:christiannefalcao.arq@gmail.com
}

\begin{abstract}
RESUMO
Considerando que a aplicação da ergonomia no ambiente construído deve ser considerada desde a concepção do projeto para aprimorar o dimensionamento do espaço e qualificar a habitação, este artigo tem como objetivo investigar os aspectos dimensionais em um apartamento de uso habitacional com uma tipologia cujos ambientes apresentam-se reduzidos, com base nas referências para o dimensionamento mínimo. Para tal, foi utilizada uma metodologia multidisciplinar, baseada no projeto participativo, com quatro etapas, a saber: 1. Estudo Conceitual; 2. Análise das condições físicas do ambiente; 3. Análise da tarefa e 4. Análise da percepção do usuário. Como resultado da síntese dessas análises, foi elaborado um diagnóstico com os principais problemas e potencialidades de cada ambiente. Por fim, os dados apresentados neste estudo têm como objetivo contribuir para a melhoria de futuros projetos de apartamentos nesta mesma tipologia, onde tenha uma arquitetura ergonomicamente mais adequada às atividades realizadas por seus usuários.
\end{abstract}

Palavras chave: ergonomia do ambiente construído; Antropometria; Análise da tarefa.

\begin{abstract}
Considering that the application of ergonomics in the built environment must be considered from the design of the project to improve the dimensioning of the space and qualify the dwelling, this article aims to investigate the dimensional aspects in an apartment of habitation use with a typology whose environments present / if reduced, based on the references for the minimum dimensioning. For that, a multidisciplinary methodology used, based on the participatory project, with four stages, namely: 1. Conceptual Study; 2. Analysis of the physical conditions of the environment; 3. Analysis of the task and 4. Analysis of the user's perception. As a result of the synthesis of these analyzes, a diagnosis was made with the main problems and potentialities of each environment. Finally, the data presented in this study aims to contribute to the improvement of future apartment projects in this same typology, where it has an architecture that is more ergonomically adequate to the activities performed by its users.
\end{abstract}

Keywords: Environment Ergonomic; Anthropometry; Task Analysis. 


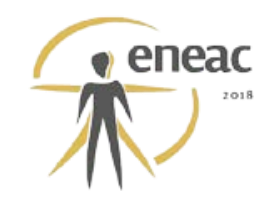

\section{INTRODUÇÃO}

A constante busca do ser humano por um espaço físico ideal para viver, dentro da esfera da habitação, engloba diversos fatores incluídos no conceito da ergonomia, tais como a qualidade de vida e conforto. Inúmeros trabalhos, como observados em Villarouco (2007), Costa Filho (2005) e Kenchian (2005), referenciam o estudo da habitação devido à sua importância dentro do ambiente construído e da sua relação de interdependência com o usuário.

Partindo do princípio em que a habitação deve atender as necessidades do usuário, a ergonomia tem como um dos fatores principais o estudo da relação usuário $x$ espaço construído, a partir da observação das atividades exercidas. Nesta direção, Boueri Filho (2004), aponta que a falta de adequação dimensional dos espaços em relação às medidas do corpo humano (Antropometria), por exemplo, é um dos grandes problemas enfrentados pelos usuários do ambiente doméstico, afetando inclusive negativamente em algumas atividades exercidas pelos mesmos.

Por outro lado, conforme apontado por Círico (2001), o rápido crescimento das cidades ocasiona um aumento significativo nos custos da construção e valor de venda dos imóveis e consequente compactação dos apartamentos para permitir um maior número de unidades por lote. A partir deste fator, a repetição de tipologias de habitações convencionais $\left(40 \mathrm{~m}^{2}\right.$ a $60 \mathrm{~m}^{2}$ ) no Brasil, oferecidas pelo mercado imobiliário para diferentes tipos de usuários, não é positiva do ponto de vista Ergonômico, visto que o bem-estar físico e mental destes não são considerados, diferente de um projeto residencial personalizado, no qual os desejos dos futuros usuários são valorizados. O entendimento das necessidades específicas de cada cliente, por parte dos arquitetos, contribui para o direcionamento de soluções projetuais mais adequadas.

Com base nestes fatores, este artigo aborda os aspectos dimensionais em um apartamento de uso habitacional com uma tipologia cujos ambientes apresentam-se reduzidos, com base nas referências para o dimensionamento mínimo. São ambientes mínimos aqueles que possuem os menores índices dimensionais permitidos pelas normas municipais, para o projeto arquitetônico ser aceito e aprovado pelos órgãos competentes e fiscalizadores.

A partir da análise proposta, pretende-se contribuir para a melhoria de futuros projetos de apartamentos nesta mesma tipologia, onde tenha uma arquitetura ergonomicamente adequada às atividades realizadas por seus usuários.

\section{METODOLOGIA}

Com base em uma avaliação multidisciplinar (FALCÃO e SOARES, 2011), a metodologia utilizada para análise do apartamento em estudo focalizou a experiência vivenciada entre pesquisador e pesquisado, com base no Projeto Participativo, conforme as etapas apresentadas na Figura 1. 


\section{(x) $^{\text {enac }}$}

Figura 1 - Etapas da avaliação multidisciplinar

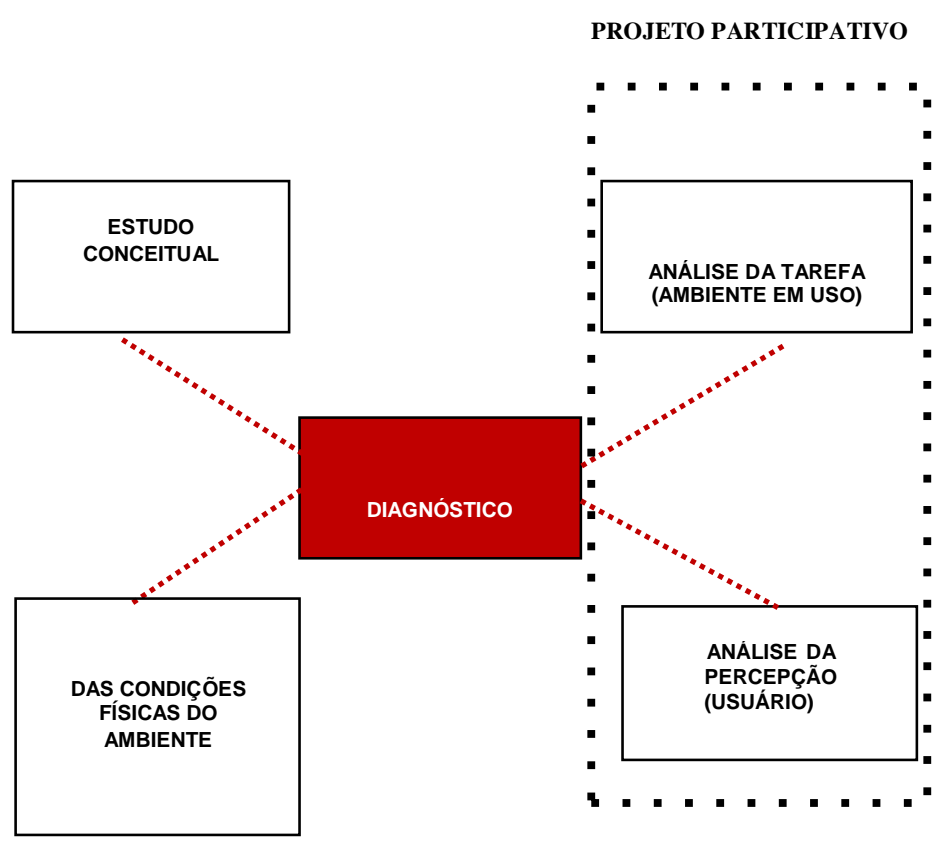

Fonte: os autores

De acordo com Gomes et al. (2017), no Projeto Participativo - PP, o usuário possui um papel ativo durante a elaboração do projeto. Busca um entendimento das necessidades físicas e funcionais do usuário e também sua percepção e satisfação quanto ao espaço habitado, partindo de análises comportamentais e dos aspectos construtivos e funcionais do ambiente.

\section{ESTUDO CONCEITUAL}

A aplicação da Ergonomia no ambiente construído deve ser considerada desde a concepção do projeto para aprimorar o dimensionamento do espaço e qualificar a habitação. Conforme apontado por Falcão e Soares (2011), a ergonomia busca o conhecimento das características humanas na projetação de sistemas que são abrigados em um ambiente, avaliando suas satisfações e insatisfações em busca de respostas para os problemas diagnosticados no processo projetual.

Com ênfase em uma abordagem multidisciplinar, apontada por Chapanís (1996) como campo da Ergonomia, Villarouco (2007), cita que a ergonomia do ambiente construído vai além das questões arquitetônicas, pois tem como foco a adaptabilidade e conformidade do espaço às tarefas e atividades que neles irão se desenvolver. Mais adiante complementa chamando a atenção para a importância da percepção que o usuário tem para com o ambiente e seus sentimentos, evidenciando a importância das questões cognitivas.

Desta forma, o ambiente construído faz parte de um sistema complexo formado por questões estruturais, sistemáticas, sociais e cognitivas, e para sua análise é fundamental entender a relação estabelecida entre as configurações físicas - formada pelos elementos tangíveis que o compõe, e os aspectos cognitivos que envolvem a percepção pelos usuários - que compreendem os elementos intangíveis.

Nos espaços habitacionais, diversas são as atividades desenvolvidas, entre outras, dormir, comer, relaxar, estudar, realizar trabalhos domésticos, ler, tomar banho, cozinhar, brincar. 


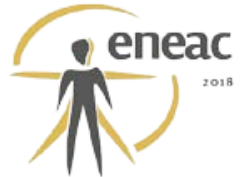

Esse grande número de atividades realizadas no ambiente doméstico, faz com que os espaços e objetos adquiram grande importância na qualidade das habitações.

Em relação às tipologias de apartamentos existentes, o usuário tem a sua disposição algumas opções previamente definidas de dimensão e programa (divisões dos espaços internos: sala, quarto, cozinha, banheiro, serviço, entre outros), localização ou preço do imóvel, e que, na maioria das vezes, a decisão da escolha fica vinculada ao menor preço. Sendo assim, considerando tais opções, é muito provável que este habitante se torne insatisfeito quanto ao atendimento de suas necessidades de moradia.

Malard (1993) aponta o ato de habitar como um processo sem fim de construir, arranjar, arrumar, modificar, cuidar e embelezar os lugares, ou seja, o ser humano se apropria dos espaços, alterando-os para dotá-los de sua própria natureza. Contudo, os edifícios residenciais impõem limitações quanto às alterações físicas e espaciais por conta das suas próprias características, resultando em um reflexo negativo nos seus usuários. Círico (2001) descreve que o arquiteto poderá através do seu projeto contribuir com imóveis que irão trazer ao usuário maior satisfação e consequentemente melhor qualidade de vida.

\subsection{O reflexo do espaço físico habitável para o usuário e suas necessidades}

Conforme apontado anteriormente, na atualidade existe uma tendência em compactar cada vez mais as habitações em edifícios multifamiliares, apesar da necessidade dos usuários por maior espaço para abrigar um número maior de móveis e equipamentos, muitas vezes ocasionada pelo aumento do número de membros da família.

De acordo com o tipo de habitação, é possível perceber os reflexos da vida de seus usuários, que representam sinais da convivência entre moradores de diferentes faixas etárias, bem como da modificação de suas necessidades, sejam estas impostas pela sociedade ou até mesmo pela constante evolução humana. $O$ não atendimento às necessidades destes usuários pode causar danos à sua saúde física pela falta de conforto, no qual o corpo não consegue obter o fundamental descanso, ou mesmo por acidentes domésticos motivados pelo mal arranjo físico em espaços reduzidos, sem levar em consideração os padrões antropométricos de dimensionamento.

Sendo assim, conforme ressalta Sumarwan (1993), o dimensionamento não adequado dos espaços, principalmente nos locais de produção, acentua os desajustes entre o usuário e o ambiente, podendo levar a constrangimentos físicos e mentais.

\subsection{Aplicação da Antropometria nos espaços habitacionais}

A visão sistêmica da ergonomia, tendo como foco principal o ser humano e sendo aplicada ao ambiente interior construído, permite gerar requisitos e parâmetros para planejamento, projeto e avaliação do ambiente e das tarefas que são executadas em seu interior, garantindo melhorias em seu desempenho (IIDA, 2005).

Dentre as diversas áreas de aplicação da ergonomia, a antropometria permite um melhor entendimento do dimensionamento no projeto de arquitetura, resaltando a importância do conhecimento do corpo humano em suas medidas e limites, sendo crucial no atendimento aos requisitos de eficiência funcional, facilidade de uso e manutenção, segurança e qualidade devida do usuário.

De acordo com Boueri Filho (2008), a área mínima de um ambiente pode ser obtida com base no arranjo espacial de acordo com as atividades exercidas, de modo que as condições de uso, acesso e articulação entre mobiliário, equipamentos e componentes, sejam adequados à essas funções. Desta forma, o espaço de atividades, caracterizado pela necessidade espacial do usuário para a realização de qualquer tarefa ou atividade, pode ser obtido considerando-se os seguintes itens (BOUERI FILHO, 2008): 


\section{$\mathrm{X}^{\text {inger }}$}

1. Posturas e movimentos do corpo humano ao executar a atividade;

2. Medidas do corpo humano;

3. Biótipo do usuário e o Padrão Antropométrico;

4. Dimensões dos equipamentos, mobiliário e componente da edificação utilizado na execução da atividade;

5. Itens de segurança de uso e operação de equipamentos e mobiliário necessário à execução da atividade.

\subsection{Definição do território}

O local escolhido para o estudo de caso foi selecionado a partir de critérios que fomentassem a realização dos objetivos da pesquisa, ou seja, a tipologia habitacional deveria apresenta características como dimensionamento inadequado e sem levar em consideração os preceitos ergonômicos. A relação entre os objetivos, a conceituação temática e o território estão evidenciadas no Quadro 1.

\section{Quadro 1 - Relação objetivo x conceituação temática $x$ território.}

\begin{tabular}{|c|c|c|}
\hline OBJETIVOS & CONCEITUAÇÃO TEMÁTICA & TERRITÓRIO \\
\hline $\begin{array}{c}\text { Analisar a } \\
\text { transformação } \\
\text { dimensional dos } \\
\text { apartamentos }\end{array}$ & $\begin{array}{c}\text { Importância do espaço } \\
\text { habitacional }\end{array}$ & $\begin{array}{c}\text { Apartamento com } \\
60 \mathrm{~m}^{2}\end{array}$ \\
\hline $\begin{array}{c}\text { Aplicar a avaliação } \\
\text { multidisciplinar na } \\
\text { análise do objeto de } \\
\text { estudo }\end{array}$ & $\begin{array}{c}\text { O reflexo do espaço habitável } \\
\text { para os usuários }\end{array}$ & $\begin{array}{c}\text { Apartamento com } \\
\text { problemas } \\
\text { ergonômicos }\end{array}$ \\
\hline $\begin{array}{c}\text { Propor o } \\
\text { dimensionamento } \\
\text { ergonômico e } \\
\text { antropométrico para o } \\
\text { objeto de estudo }\end{array}$ & $\begin{array}{c}\text { Ergonomia e antropometria no } \\
\text { espaço habitável }\end{array}$ & $\begin{array}{c}\text { Dimensionamento } \\
\text { inadequado }\end{array}$ \\
\hline \multicolumn{2}{|c|}{} & \\
\hline
\end{tabular}

Fonte: os autores

Com base nestes fatores, o apartamento escolhido pertence à uma das torres do Condomínio Vila Jardim, localizado em Jardim São Paulo - Recife/PE. Este possui uma área de $60 \mathrm{~m}^{2}$, abrigando uma família com 3 pessoas (1 casal e 1 filha). O apartamento encontra-se dividido em 3 zonas - Social, Íntima e Serviço, no qual estão evidenciadas na Figura 2. 


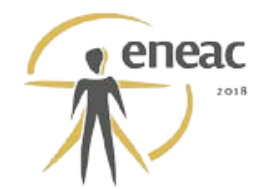

Figura 2 - Zoneamento do apartamento

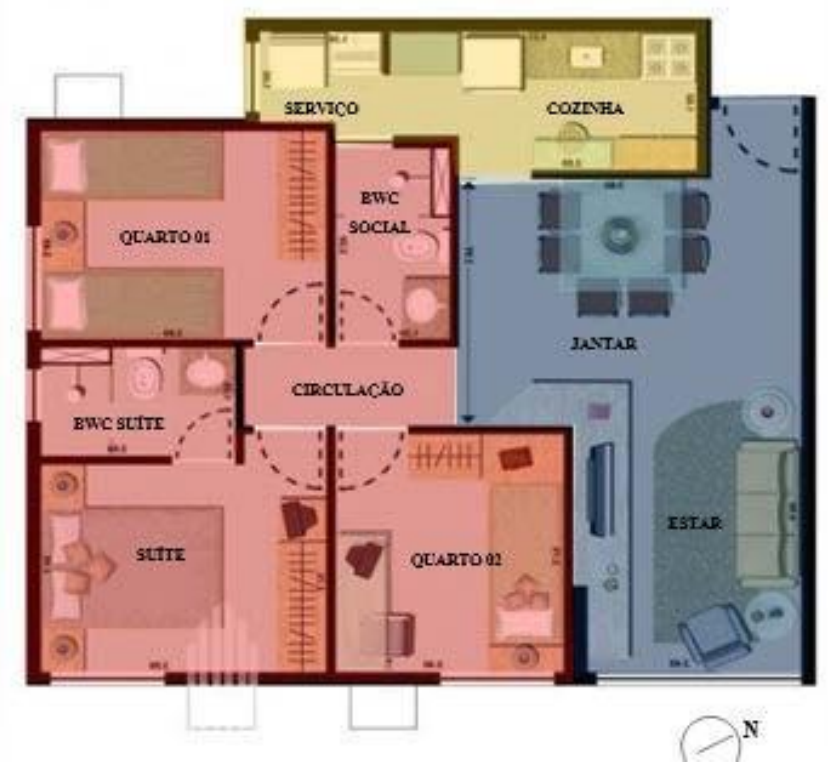

Fonte: os autores

O principal usuário do objeto de estudo - a esposa - realiza suas atividades no período da manhã e noite para realizar o preparo das refeições e também limpeza e arrumação dos ambientes. Esta, necessita de um apartamento onde o dimensionamento adequado e 0 layout seja o elemento determinante na utilização do espaço e do seu conforto, com uma disposição racional do processo produtivo e áreas de movimentação, manuseio e condições humanas de trabalho - ventilação, iluminação, acessibilidade, entre outros.

\section{ANÁLISE DAS CONDIÇÕES FÍSICAS DO AMBIENTE}

Quando falamos em condições físicas, os fatores a serem abordados não correspondem apenas à disposição do arranjo físico, mas também dos fatores naturais que incidem sobre aquele ambiente, como por exemplo a orientação solar e a incidência dos ventos.

Na primeira visita ao ambiente, foi aplicada a ferramenta Walkthrough para o registro dos aspectos físicos do ambiente, assim como os pontos positivos e negativos. Nesta etapa foram identificados todos os condicionantes físicos e ambientais a partir de um levantamento de dados: Dimensão dos ambientes, conforto ambiental, arranjo físico, condições de acessibilidade, cores e materiais de revestimento.

\section{ANÁLISE DA TAREFA}

Nesta etapa foi identificado o desempenho das tarefas realizadas no ambiente pelo usuário, análise dos fluxos, identificação de atividades primárias e secundárias e a sua natureza, exigências importantes como segurança, necessidade de acessórios, dimensionamento do espaço e agrupamento do layout (móveis), número de pessoas atendidas, entre outros fatores importantes. 


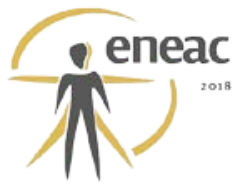

Figura 3 - Análise do comportamento do usuário

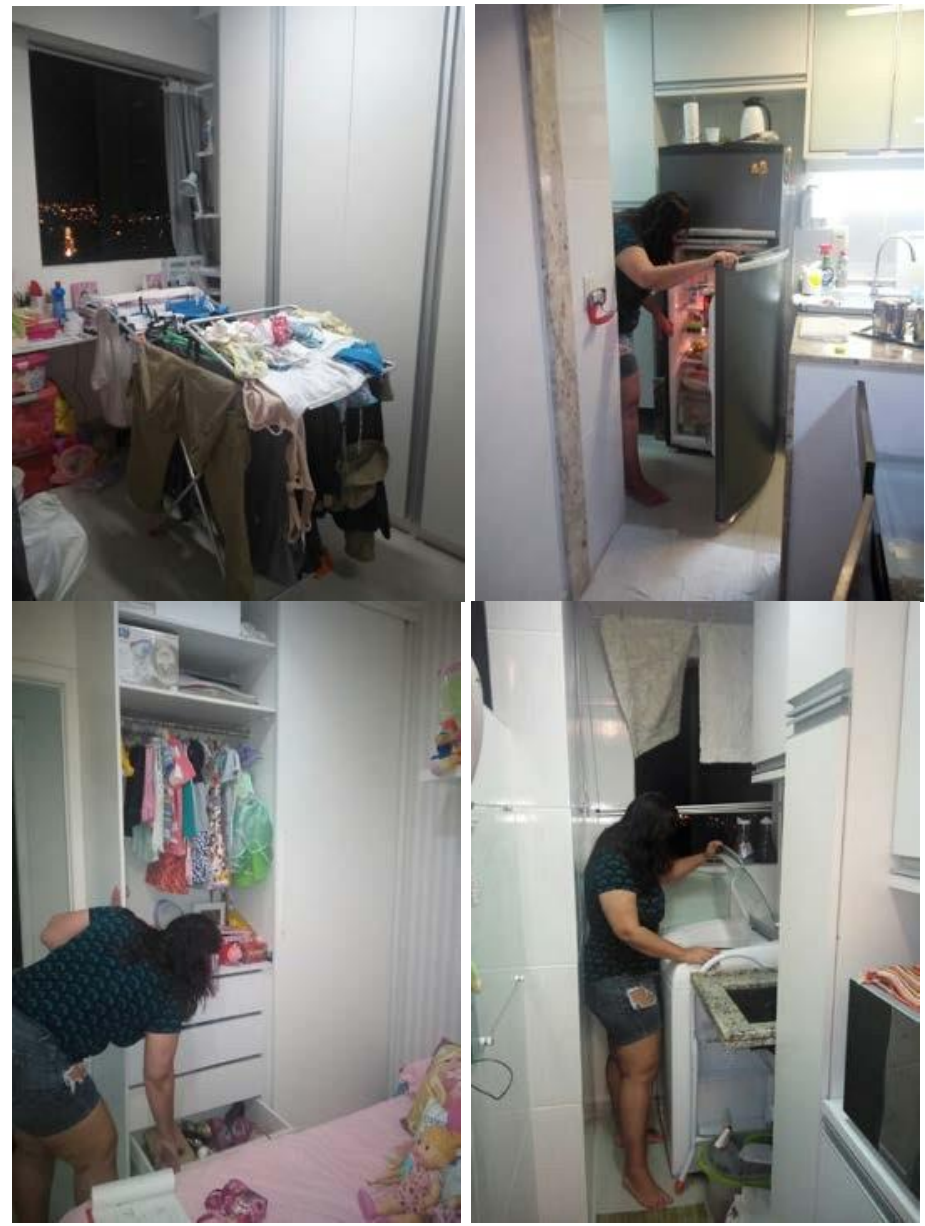

Fonte: Maria Cristina Pollesel, 2017

Analisando as imagens acima, é perceptível que os ambientes possuem o arranjo físico e a divisão espacial como elemento dificultador para realização de algumas atividades desenvolvidas pelo usuário. Devido à incorreta disposição do arranjo físico, como principalmente no ambiente da cozinha, há uma certa dificuldade no desempenho das atividades pelo usuário e consequentemente comprometendo a sua segurança.

Visto que a cozinha é um dos principais ambientes utilizados pelos usuários, percebe-se que esta deve ter uma atenção especial devido a seu incorreto dimensionamento e a desorganização das zonas - armazenagem, limpeza, preparo de alimentos e cocção - no qual deveriam ser integradas para facilitar a execução das atividades diárias.

\section{ANÁLISE DA PERCEPÇÃO DO USUÁRIO}

Esta etapa teve como objetivo identificar os valores sociais e culturais dos usuários. Ou seja, identificam-se a intensidade em que o ambiente afeta o usuário e vice-versa, o que existe no ambiente e o que esse usuário deseja para aquele mesmo espaço. Para tal, uma entrevista foi realizada com os usuários para identificação de sua percepção em relação ao ambiente em que vivem com base nas seguintes perguntas: 1. Como minha casa é? e 2. Como eu gostaria que minha casa fosse? 


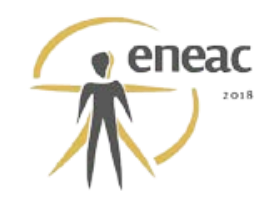

De acordo com a análise das respostas dos usuários em relação ao apartamento em que habitam, ficou evidente o desejo por um ambiente aconchegante no que diz respeito ao dimensionamento adequado às suas necessidades rotineiras, expresso através da seguinte afirmação: "Para mim um apartamento ideal é aquele onde tenho tudo nas mãos, tudo é acessível e que não tenha limitação de dimensionamento, pois me sinto enclausurada várias vezes ao dia. Sei que é um apartamento pequeno, porém é mal dimensionado. Infelizmente muitos profissionais não pensam em quem vai habitar o ambiente."

\section{DIAGNÓSTICO}

Esta etapa corresponde a análise realizada através das observações dos pesquisadores, de acordo com os dados cruzados da avaliação física e percepção do usuário, no qual mostra o que é possível para o ambiente em estudo e as qualidades desejadas que sejam apropriadas ao contexto espacial e compatíveis não só com os desejos do cliente, mas também com suas necessidades.

Com base nos resultados, foi verificado que a cozinha possui muitos pontos negativos, consequência de um arranjo físico ruim. Porém, os fatores apontados pelo seu principal usuário, a esposa, são possíveis de serem executados.

\subsection{Principais problemas identificados}

Sala de estar:

- Distância inadequada entre sofá e televisão (Figuras 4 e 5);

- Baixa iluminação artificial;

Figura 4 - Problemas no dimensionamento da sala de estar.

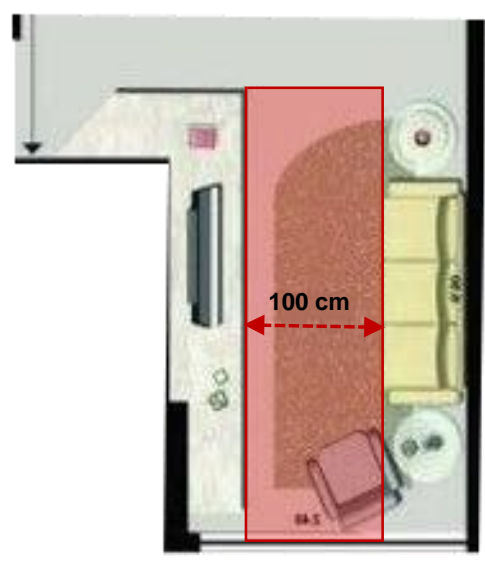

Fonte: os autores
Figura 5 - Linhas de visão adequadas.

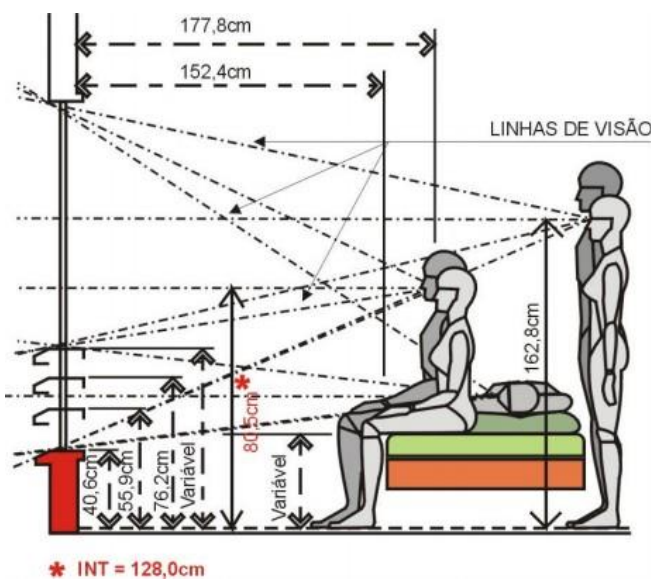

Fonte: CíRICO, 2001, adaptado de PANERO e ZELNIK (1979). 


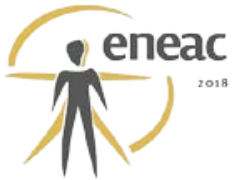

Sala de Jantar:

- Espaço inadequado entre cadeira e circulação (Figuras 6 e 7);

- Baixa iluminação artificial;

Figura 6 - Problemas na circulação.

Figura 7 - Circulação adequada.

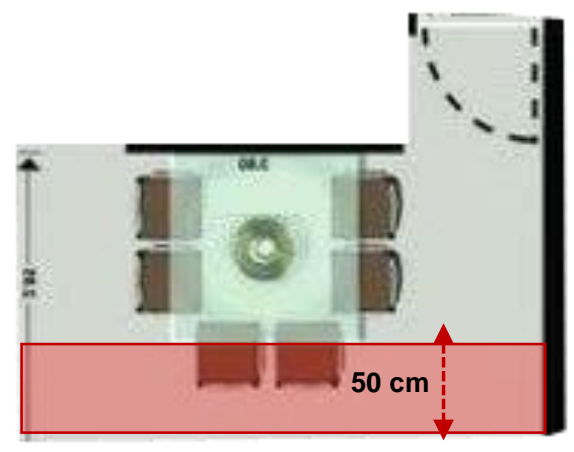

Fonte: os autores

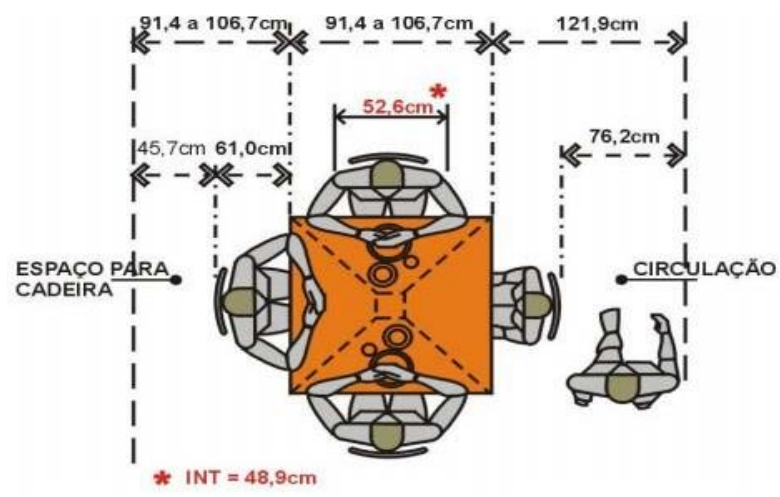

Fonte: CÍRICO, 2001, adaptado de PANERO e ZELNIK (1979).

Cozinha:

- Distribuição desordenada de eletrodomésticos no ambiente;

- Falta de bancada de apoio próximo ao fogão, na zona de cocção;

- Microondas localizado distante da área de cocção;

- Dimensionamento inadequado de acordo com os equipamentos, gerando conflitos na circulação e dificuldade no desempenho das atividades diárias (Figuras 8 e 9);

- As zonas (cocção, limpeza, preparação e armazenagem) não possuem uma interligação adequada;

- Armários superiores fora do alcance dos usuários (Figura 9);

- Necessidade de coifa ou exaustor na zona de cocção;

- Baixa iluminação artificial; 


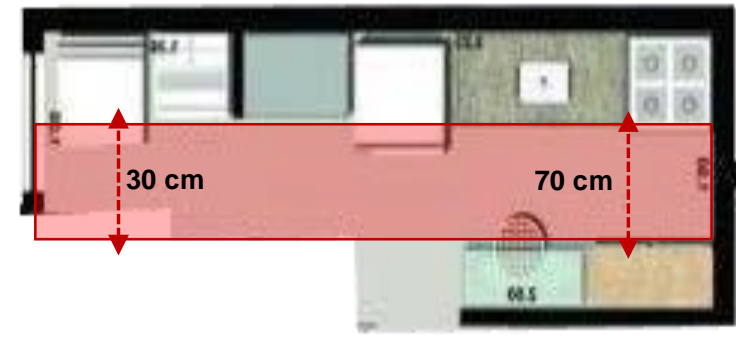

Fonte: os autores

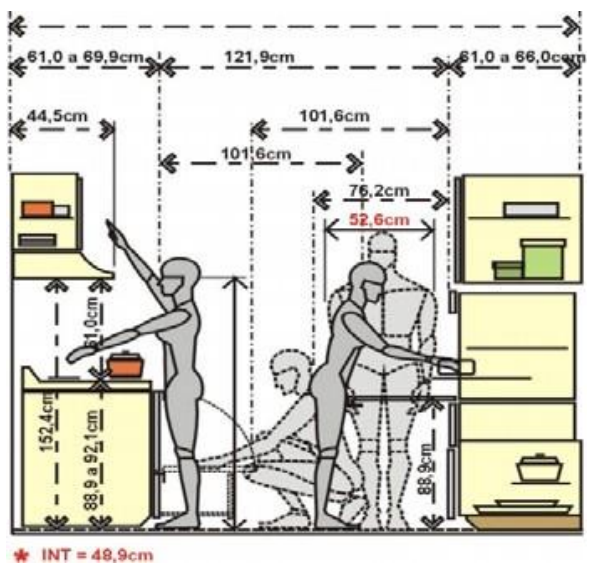

Fonte: CíRICO, 2001, adaptado de PANERO e ZELNIK (1979).

Área de serviço:

- Dimensionamento inadequado para abrigar os equipamentos existentes;

- A profundidade da bancada do tanque dificulta a lavagem de roupas pelos usuários;

- Armários superiores fora do alcance aos usuários;

- Circulação na máquina de lavar roupas insuficiente;

- Ausência de varal para estender roupas (este é colocado no quarto 1);

Quarto Suite:

- Pouco espaço para dimensionar o mobiliário e equipamentos adequadamente, comprometendo a circulação entre os mesmos, que conforme Boueri Filho (2008), não deve ser menor que 60 centímentros (Figura 10);

- Em função do espaço reduzido do guarda-roupas, é utilizado também o do quarto 1 como complementar para guardar as roupas do casal.

- Dimensionamento inadequado do banheiro dificulta o uso do armário abaixo do lavatório. O mesmo problema foi também identificado no banheiro social. 


\section{(x) $^{\text {enac }}$}

Figura 10 - Problemas dimensionais na suíte.

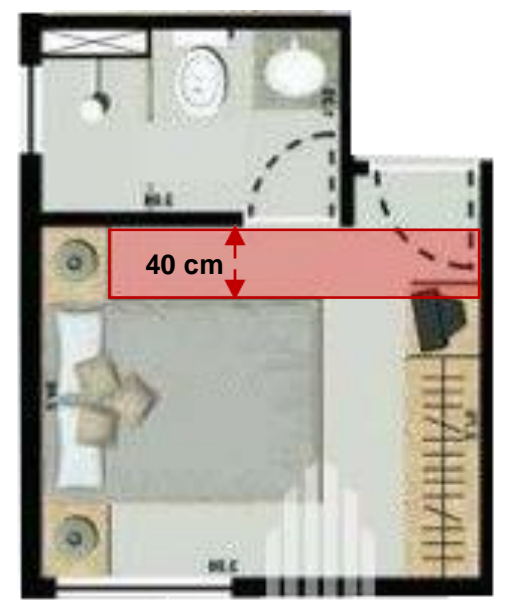

Fonte: os autores

\subsection{Principais potenciais identificados}

Nos ambientes foi verificado boas condições de ventilação e iluminação natural. Na cozinha, os móveis e eletrodomésticos existentes poderão ser preservados, pois encontram-se em bom estado de conservação, sendo necessário o ajuste da altura das bancadas e armários.

\section{CONCLUSÃO}

A avaliação multidisciplinar a partir de um projeto participativo tem papel fundamental no entendimento da relação usuário-ambiente, uma vez que traz a opinião do usuário e não apenas a visão do projetista. Neste panorama, pode-se afirmar que a ergonomia, cujo foco está centrado no ser humano e nas atividades por ele/ela desenvolvidas, é de extrema importância para conferir uma percepção global necessária à consecução de espaços mais eficazes. Modelos de avaliação pré e pós ocupação, devem ser considerados na concepção de espaços ergonomicamente adequados, no início do projeto, visando identificar o desejo do usuário e transmitir para o mesmo a configuração espacial do ambiente construído.

Dando continuidade a este estudo, pretende-se traçar diretrizes para um adequado dimensionamento de acordo com os usuários do apartamento em análise, integrando os objetivos do projeto, a conceituação temática e as peculiaridades do território em análise, propiciando uma viabilidade econômica ao evitar as constantes reformas para ajustes do espaço às necessidades de seus habitantes.

\section{REFERÊNCIAS BIBLIOGRÁFICAS}

BOUER FILHO, José J. A contribuição da Ergonomia na Formação do Arquiteto: 0 Dimensionamento dos Espaços da Habitação. Tese (livre docência em Arquitetura e Urbanismo). Universidade de São Paulo, São Paulo, 2004.

BOUERI FILHO, José J. Espaço de Atividades. São Paulo: Estação das Letras e Cores, 2008.

CHAPANÍS, Alphonse. Human Factors in system engineering. New Youk: John Wiley Press, 1996. 


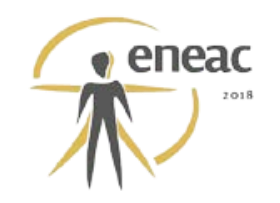

CÍRICO, Luiz Alberto. Por dentro do espaço habitável: uma avaliação ergonômica de apartamentos e seus reflexos nos usuários. Dissertação (mestrado) - Universidade Federal de Santa Catarina, Engenharia de Produção, 2001.

COSTA FILHO, Lourival L. Discussão sobre a definição dimensional em apartamentos: contribuição à ergonomia do ambiente construído. Dissertação (mestrado) - Universidade Federal de Pernambuco. CAC. Design, 2005.

FALCÃO, Christianne; SOARES, Marcelo. Ergonomia e Análise Multidisciplinar do Ambiente Construído. In: Anais do III Encontro Nacional de Ergonomia do Ambiente Construído e IV Seminário Brasileiro de Acessibilidade Integral, ENEAC. João Pessoa - PB, 2011.

GOMES, Larissa; FELIPE, Mariana; FALCÃO, Christianne. Avaliação pós-ocupação e projeto participativo: estudo de caso de uma cozinha residencial unifamiliar. In: Anais do V Simpósio Brasileiro de Qualidade do Projeto no Ambiente Construído, SBQP. João Pessoa-PB, 2017.

IIDA, Itiro. Ergonomia: Projeto e Produção. 2ª Ed. São Paulo: Editora Edgard Blucher. 2005

KENCHIAN, Alexandre. Estudo de modelos e técnicas para projeto e dimensionamento dos espaços da habitação. Dissertação (Mestrado - Área de Concentração: Tecnologia da Arquitetura) FAUUSP, 2005.

MALARD, M. L. Os objetos do quotidiano e a ambiência, Anais do $2^{\circ}$ Encontro de Conforto no Ambiente Construído, Florianópolis, 1993, p. 36.

SUMARWAN, $U$. Socioeconomic and psychological variables influencing house hold debt. lowa, Tese de PhD, Universidade do Estado de lowa. USA, 1993.

VILLAROUCO, Vilma. O ambiente está adequado? In: Anais do I Encontro Nacional de Ergonomia do Ambiente Construído e II Seminário Brasileiro de Acessibilidade Integral, ENEAC. Recife-PE, 2007. 